Bond University

Research Repository

\title{
Safety of neuraminidase inhibitors for influenza
}

Jones, Mark; Del Mar, Chis

Published in:

Expert Opinion on Drug Safety

DOI:

10.1517/14740338.5.5.603

Licence:

Free to read

Link to output in Bond University research repository.

Recommended citation(APA):

Jones, M., \& Del Mar, C. (2006). Safety of neuraminidase inhibitors for influenza. Expert Opinion on Drug Safety, 5(5), 603-608. https://doi.org/10.1517/14740338.5.5.603

\section{General rights}

Copyright and moral rights for the publications made accessible in the public portal are retained by the authors and/or other copyright owners and it is a condition of accessing publications that users recognise and abide by the legal requirements associated with these rights.

For more information, or if you believe that this document breaches copyright, please contact the Bond University research repository coordinator. 


\title{
Bond University
}

\section{ePublications@bond}

9-1-2006

\section{Safety of neuraminidase inhibitors for influenza}

\author{
Mark Jones \\ University of Queensland \\ Chris Del Mar \\ Bond University, chris_del_mar@bond.edu.au
}

Follow this and additional works at: http://epublications.bond.edu.au/hsm_pubs

\footnotetext{
Recommended Citation

Mark Jones and Chris Del Mar. (2006) "Safety of neuraminidase inhibitors for influenza" ,, .

http://epublications.bond.edu.au/hsm_pubs/23

This Journal Article is brought to you by the Faculty of Health Sciences \& Medicine at ePublications@bond. It has been accepted for inclusion in Faculty of Health Sciences \& Medicine Publications by an authorized administrator of ePublications@bond. For more information, please contact Bond University's Repository Coordinator.
} 


\section{Expert Opinion}
1. Introduction
2. Safety profile of oseltamivir
3. Safety profile of zanamivir
4. Conclusion
5. Expert opinion

\section{Anti-infectives}

\section{Safety of neuraminidase inhibitors for influenza}

\author{
Mark Jones ${ }^{\dagger} \&$ Chis Del Mar \\ ${ }^{\dagger}$ University of Queensland, Princess Alexandra Hospital, School of Population Health, Woolloongabba, \\ Queensland 4102, Australia
}

Neuraminidase inhibitors, oseltamivir and zanamivir, are used for the treatment of, and protection from, influenza. The safety of these compounds has been assessed in systematic reviews. However, the data presented are somewhat limited by the paucity of good quality adverse event data available. The majority of safety outcomes are based on evidence from just one or two randomised controlled trials. The results of the systematic reviews suggest that neuraminidase inhibitors have a reasonable side effect and adverse effect profile if they are to be used to treat or protect patients against a life-threatening disease. However, if these compounds are to be prescribed in situations in which avoidance of inconvenience or minor discomfort is hoped for, then the balance of harms to benefits will be more difficult to judge.

Keywords: influenza, neuraminidase inhibitor, oseltamivir, zanamivir

Expert Opin. Drug Saf. (2006) 5(5):xxx-xxx

\section{Introduction}

\subsection{Influenza the illness}

Although the influenza virus usually causes only minor symptoms (headache, runny nose, dry cough, fever, muscle pain and sore throat) for about one week, and most recover without requiring treatment, it can be fatal. People at threat are the very young, the elderly and those with comorbidity, especially if the immune system is compromised, including almost any serious health condition, such as cancer, lung disease, heart or kidney problems. The mode of death often includes dehydration and pneumonia. Three to five million cases of influenza lead to the death of between $250,000-500,000$ people annually [101].

Influenza is so infectious it gives rise to seasonal epidemics in which $5-20 \%$ of the population become infected. The disease is spread from person to person via respiratory droplets caused by coughing and sneezing, or by fomite transmission (in which the virus is picked up on fingers and inadvertently transferring it to the respiratory mucosa). The incubation period for influenza is typically $1-4$ days. Adults are able to infect others from a day before symptoms develop to $\sim 5$ days afterwards, although children can do so for longer - up to 10 days or more.

Influenza can be classified in several ways: the two main types (Influenza A and B) and several subtypes based on the detection of two viral surface proteins; for example, Type $\mathrm{A}(\mathrm{H} 3 \mathrm{~N} 2)$ and $\mathrm{A}(\mathrm{H} 1 \mathrm{~N} 1)$. $\mathrm{H}$ represents haemagglutinin and $\mathrm{N}$ neuraminidase. The haemagglutinin antigen enables the influenza virus to enter human respiratory epithelium cells, and the neuraminidase antigen allows the release of newly replicated viral particles from infected cells. Instability of these proteins leads to minor genetic changes in the structure of the viruses, called antigenic drift, generating new viral strains, sufficiently different from previously exposed strains to require new exposure to the immune system to generate protection (unlike, for example, most childhood viral infections, which once encountered are never experienced again). This is the cause of seasonal influenza. Major genetic changes, antigenic shift, occur infrequently 
(three times in the last century) and these give rise to global pandemics that have claimed the lives of millions, including the young and healthy. In modern epidemics, most influenza-related deaths are due to exacerbation of underlying cardiopulmonary disease, and pneumonia is a relatively minor contributor. However, this ratio is reversed in pandemic years when most deaths are due to pneumonia.

\subsection{Neuraminidase inhibitors}

Neuraminidase inhibitors differ from the pre-existing antiviral agents, amantadine and rimantadine, which are only effective in the treatment of type A influenza. Amantadine and rimantadine have a stronger side effect profile, including severe adverse reactions, and there are problems with the induction of resistance with Influenza Type A.

Neuraminidase inhibitors can be used for treatment of, as well as the prophylaxis against influenza type A and type B. They block the activity of the viral neuraminidase enzyme needed to enable new viral particles from being released out of infected cells. There are two neuraminidase inhibitors currently available: zanamivir (Relenza ${ }^{\circledR}$ made by Glaxo Wellcome), a powder that is normally inhaled, and oseltamivir (Tamiflu ${ }^{\circledR}$, co-developed by Gilead Sciences, and Hoffmann-La Roche), an oral agent available as both a suspension and a tablet. In addition, there are other neuraminidase inhibitors being developed that could potentially be available in the not-too-distant future.

The FDA has approved the use of oseltamivir for the treatment of uncomplicated influenza in patients aged $\geq 1$ year whose symptoms have not lasted $>2$ days, and for the prevention of influenza in adults and children aged $\geq 1$ year. However, it acknowledges that treatment efficacy has not been established in subjects with chronic cardiac disease or respiratory disease and prevention efficacy has not been established in immunocompromised patients. Oseltamivir is not approved for infants aged $<1$ year because preclinical studies in juvenile rats have found extremely toxic levels of drug in the brains of the rats after application of a single dose. This is most probably because of permeability of the immature blood-brain barrier [102]. Zanamivir has been approved for persons aged $\geq 7$ years for the treatment of uncomplicated influenza virus but not for use in prevention of influenza (prophylaxis). It is not recommended for people with underlying respiratory disease such as asthma as some people with these conditions have experienced serious side effects such as wheezing and shortness of breath and it has not been shown to be effective in this population [103]. The European Medicines Agency (EMA) has given a similar indication for treatment with oseltamivir, although their indication for prevention differs. Postexposure prevention is indicated for adults and adolescents aged $\geq 13$ years, whereas seasonal prevention of influenza should only be considered in adults and adolescents aged $\geq 13$ years in exceptional situations [104]. Zanamivir is indicated for treatment of adults and adolescents aged $\geq 12$ years, but is not yet approved for prophylaxis [105].
It is the safety profile of neuraminidase inhibitors which is the subject of this review. The review is based primarily on data from the most recent systematic review of the efficacy and safety of antiviral agents for the treatment and prevention of influenza in healthy adults [1], and a Cochrane systematic review of neuraminidase inhibitors for preventing and treating influenza in children [2]. It should be noted that the systematic review for children was not able to identify any prophylaxis studies of neuraminidase inhibitors acceptable for inclusion, so safety data for oseltamivir or zanamivir in a prophylaxis role for children is not presented in this review. A systematic review of randomised, controlled trials is generally regarded as the highest level of evidence attainable for healthcare interventions. In addition, it has been reported that non-randomised studies generally tend to underestimate the risk of harms from medical interventions compared with randomised studies [3].

\section{Safety profile of oseltamivir}

According to the manufacturer, the adverse events occurring more frequently in patients taking oseltamivir compared to placebo are nausea, vomiting, bronchitis, insomnia and vertigo for adults in treatment studies; vomiting, abdominal pain, epistaxis, ear disorder and conjunctivitis for paediatric patients in treatment studies; and nausea, vomiting, diarrhoea, abdominal pain, dizziness, headache, insomnia, vertigo and fatigue for adults and adolescents in prophylaxis studies [106]. The following data comes from the most recent systematic review of the efficacy and safety of antiviral agents for the treatment and prevention of influenza [1] and a Cochrane systematic review of neuraminidase inhibitors for preventing and treating influenza in children [2].

\subsection{Prophylaxis in adults}

In a prophylaxis role, oral oseltamivir at $75 \mathrm{mg} / \mathrm{day}$ is associated with significantly more nausea compared to placebo (OR: 1.8, 95\% CI: $1.1-2.9$ ). The number of people taking $75 \mathrm{mg} /$ day that would result in one additional case of nausea ('number needed to harm') is 20 (95\% CI: 13 - 63). Oral oseltamivir at the higher dose of $150 \mathrm{mg}$ per day is also associated with significantly more nausea compared with placebo (OR: 2.3, 95\% CI: 1.3 - 3.9). The number needed to harm for the higher dose is 13 (95\% CI: 9 - 33). The increased vomiting associated with oseltamivir use is not significantly different from that experienced by those taking placebo: oral oseltamivir at $75 \mathrm{mg} / \mathrm{day}$, OR: 2.3 , (95\% CI: $0.9-6.0)$, at $150 \mathrm{mg} /$ day, OR: 3.6, (95\% CI: $0.8-15.8)$. Other reported adverse events are similarly not significantly different between oseltamivir at $75 \mathrm{mg} / \mathrm{day}$ and placebo: diarrhoea (OR: 0.6, 95\% CI: $0.3-1.2$ ), abdominal pain (OR: 1.0, 95\% CI: 0.5 - 2.0) and other adverse events (OR: 1.0, 95\% CI: 0.6 - 1.6), Table 1. Withdrawals due to gastrointestinal events were too infrequent to provide meaningful results. 
Table 1. Safety outcomes for oral oseltamivir used for prophylaxis in adults.

\begin{tabular}{|c|c|c|c|c|c|}
\hline $\begin{array}{l}\text { Dose and adverse } \\
\text { outcome }\end{array}$ & Number of trials & $\begin{array}{l}\text { Oseltamivir group } \\
\mathrm{n} / \mathrm{N}(\%)\end{array}$ & $\begin{array}{l}\text { Placebo group } \\
\text { n/N (\%) }\end{array}$ & $\begin{array}{l}\text { Odds ratio } \\
(95 \% \mathrm{Cl})\end{array}$ & P-value \\
\hline \multicolumn{6}{|l|}{75 mg/day } \\
\hline Nausea & $2[5,6]$ & $71 / 675(10.5)$ & $23 / 413(5.6)$ & $1.8(1.1-2.9)$ & 0.02 \\
\hline Vomiting & $2[5,6]$ & 20/675 (3.0) & $6 / 413(1.5)$ & $2.3(0.9-6.0)$ & 0.09 \\
\hline Diarrhoea & $1[5]$ & $13 / 155(8.4)$ & $21 / 153(13.7)$ & $0.6(0.3-1.2)$ & 0.14 \\
\hline Abdominal pain & $1[5]$ & 18/155 (11.6) & 18/153 (11.8) & $1.0(0.5-2.0)$ & 0.97 \\
\hline Other adverse events & $1[5]$ & $46 / 155(29.7)$ & $47 / 153(30.7)$ & $1.0(0.6-1.6)$ & 0.84 \\
\hline \multicolumn{6}{|l|}{150 mg/day } \\
\hline Nausea & $1[5]$ & $76 / 520(14.6)$ & 18/259 (6.9) & $2.3(1.3-3.9)$ & 0.002 \\
\hline Vomiting & $1[5]$ & $14 / 520(2.7)$ & $2 / 260(0.8)$ & $3.6(0.8-15.8)$ & 0.09 \\
\hline
\end{tabular}

Table 2. Safety outcomes for oral oseltamivir (150 mg/day) used as treatment (adults).

\begin{tabular}{lllllll}
\hline Safety outcome & Number of trials & $\begin{array}{l}\text { Oseltamivir group } \\
\mathbf{n} / \mathbf{N}(\%)\end{array}$ & $\begin{array}{l}\text { Placebo group } \\
\mathbf{n} / \mathbf{N}(\mathbf{\%})\end{array}$ & $\begin{array}{l}\text { Odds ratio } \\
\mathbf{( 9 5 \%} \mathbf{~ C l )}\end{array}$ & P-value \\
\hline Cough* & $1[7]$ & $125 / 134(93.3)$ & $127 / 139(91.4)$ & $1.3(0.5-3.2)$ & 0.55 \\
Headache* & $1[7]$ & $119 / 134(88.8)$ & $124 / 139(89.2)$ & $1.0(0.5-2.0)$ & 0.92 \\
Diarrhoea & $1[8]$ & $14 / 154(9.1)$ & $24 / 159(15.1)$ & $0.6(0.3-1.1)$ & 0.11 \\
Nasal symptoms* & $1[7]$ & $93 / 134(69.4)$ & $101 / 139(72.7)$ & $0.9(0.5-1.4)$ & 0.55 \\
Nausea & $2[8,9]$ & $91 / 565(16.1)$ & $31 / 363(8.5)$ & $1.8(0.7,4.4)$ & 0.20 \\
All adverse events & $1[8]$ & $71 / 154(46.1)$ & $89 / 159(56.0)$ & $0.7(0.4-1.1)$ & 0.08 \\
\hline
\end{tabular}

*Based on a symptom severity score of $\geq 1$, where $0=$ no symptom, $1=$ minor, $2=$ moderate, $3=$ severe.

\subsection{Treatment in adults}

In a treatment role, there is insufficient evidence to confirm oral oseltamivir is associated with increased adverse events compared to placebo. It appears that 150 - $300 \mathrm{mg}$ daily may be associated with more nausea than placebo, but any differences are not statistically significant (OR: 1.8, 95\% CI: $0.7-4.4)$. Other adverse events compared included: cough (OR: 1.3, 95\% CI: $0.5-3.2$ ), headache (OR: 1.0, 95\% CI: 0.5 - 2.0), diarrhoea (OR: 0.6, 95\% CI 0.3 - 1.1), nasal symptoms (congestion, rhinitis, dry or sore throat) (OR: 0.9, 95\% CI: $0.5-1.4$ ) and all types of adverse events (OR: 0.7, 95\% CI: $0.4-1.1$ ), Table 2 .

\subsection{Treatment in children}

Oral oseltamivir in a treatment role in children is associated with significantly more vomiting compared with placebo (OR: 1.7, $95 \%$ CI: $1.2-2.5$ ), resulting in a number needed to harm of 18 (95\% CI: $11-67)$. Surprisingly there appears to be no such effect for nausea (OR: 0.8, 95\% CI: $0.4-1.5$ ). Other reported adverse events are similar for oseltamivir and placebo groups: any adverse event (OR: 0.9, 95\% CI: $0.7-1.1$ ), serious adverse events (OR: 2.0, 95\% CI: $0.6-6.7$ ), adverse events leading to study withdrawal (OR: 1.0, 95\% CI: $0.4-2.7$ ), and diarrhoea (OR: 0.8, 95\% CI: $0.5-1.3$ ), Table 3.

\section{Safety profile of zanamivir}

The manufacturer reports the following side effects from zanamivir: nausea, diarrhoea and sinusitis. But the incidence of these adverse events is reported similar for treated patients using active drug and placebo. Bronchospasm and decline in lung function has been reported by some patients receiving zanamivir, mainly but not exclusively, in patients with underlying airway disease (such as asthma or chronic obstructive pulmonary disease) [107].

\subsection{Prophylaxis in adults}

The most recent systematic review of the efficacy and safety of antiviral agents for the treatment and prevention of influenza did not report on adverse events for zanamivir in a prophylaxis role [1]. Therefore, data from a previous systematic review are presented [4]. All adverse events were pooled and the proportions of individuals with an adverse event in the two groups were: zanamivir: $7.5 \%$ (95\% CI: $6.2-9.2 \%)$ versus placebo: $7.8 \%$ (95\% CI: $6.4-9.7 \%)$.

\subsection{Treatment in adults}

Zanamivir as treatment is not associated with increased adverse events of any type compared with placebo [1]. 
Table 3. Safety outcomes for oral oseltamivir used as treatment (children).

\begin{tabular}{|c|c|c|c|c|c|}
\hline Safety outcome & Number of trials & $\begin{array}{l}\text { Oseltamivir group } \\
\mathrm{n} / \mathrm{N}(\%)\end{array}$ & $\begin{array}{l}\text { Placebo group } \\
\text { n/N (\%) }\end{array}$ & $\begin{array}{l}\text { Odds ratio }(95 \% \\
\mathrm{Cl})\end{array}$ & P-value \\
\hline Any adverse event & $2[10,11]$ & $251 / 514(48.8)$ & $269 / 515(52.2)$ & $0.9(0.7-1.1)$ & 0.3 \\
\hline $\begin{array}{l}\text { Serious adverse } \\
\text { events }\end{array}$ & $2[10,11]$ & $8 / 514(1.6)$ & $4 / 515(0.8)$ & $2.0(0.6-6.7)$ & 0.3 \\
\hline $\begin{array}{l}\text { Adverse events } \\
\text { leading to study } \\
\text { withdrawal }\end{array}$ & $2[10,11]$ & $8 / 514(1.6)$ & $8 / 515(1.6)$ & $1.0(0.4-2.7)$ & 1 \\
\hline Nausea & $2[10,11]$ & $17 / 514(3.3)$ & $22 / 515(4.3)$ & $0.8(0.4-1.5)$ & 0.4 \\
\hline Vomiting & $2[10,11]$ & $76 / 514(14.8)$ & $48 / 515(9.3)$ & $1.2(1.1-2.5)$ & 0.008 \\
\hline Diarrhoea & $2[10,11]$ & $40 / 514(7.8)$ & $49 / 514(9.5)$ & $0.8(0.5-1.3)$ & 0.3 \\
\hline
\end{tabular}

Table 4. Safety outcomes for zanamivir in a treatment role in adults and children.

\begin{tabular}{llllll}
\hline $\begin{array}{l}\text { Age group, } \\
\text { Safety outcome }\end{array}$ & Number of trials & $\begin{array}{l}\text { Zanamivir group } \\
\mathbf{n} / \mathbf{N}(\%)\end{array}$ & $\begin{array}{l}\text { Placebo group } \\
\mathbf{n} / \mathbf{N}(\%)\end{array}$ & $\begin{array}{l}\text { Odds ratio (95\% } \\
\mathbf{C l})\end{array}$ & P-value \\
\hline $\begin{array}{l}\text { Adults } \\
\text { Cough }\end{array}$ & $2[12,13]$ & $12 / 520(2.3)$ & $14 / 523(2.7)$ & $1.4(0.1-13.5)$ & 0.77 \\
Headache & $2[14,15]$ & $16 / 891(1.8)$ & $9 / 461(2.0)$ & $0.9(0.4-2.0)$ & 0.74 \\
Diarrhoea & $4[12-15]$ & $37 / 1431(2.6)$ & $28 / 984(2.8)$ & $0.8(0.4-1.6)$ & 0.51 \\
Nasal symptoms & $3[12,13,15]$ & $63 / 1354(4.7)$ & $61 / 945(6.5)$ & $1.0(0.5-2.0)$ & 0.95 \\
$\begin{array}{l}\text { Nausea } \\
\text { Bronchitis or }\end{array}$ & $3[12,15,16]$ & $27 / 1235(2.2)$ & $28 / 832(3.4)$ & $0.6(0.4-1.1)$ & 0.10 \\
pneumonia & $3[12,13,15]$ & $25 / 1354(1.8)$ & $30 / 945(3.2)$ & $0.7(0.2-2.3)$ & 0.59 \\
All adverse events & $3[12,13,15]$ & $181 / 597(30.3)$ & $187 / 562(33.3)$ & $0.9(0.7-1.1)$ & 0.34 \\
$\begin{array}{l}\text { Children } \\
\text { Any adverse event }\end{array}$ & $1[17]$ & & & & $0.8(0.5-1.2)$ \\
$\begin{array}{l}\text { Serious adverse } \\
\text { events }\end{array}$ & $1[17]$ & $48 / 224(21.4)$ & $65 / 247(26.3)$ & 0.3 & 0.3 \\
\hline
\end{tabular}

A detailed breakdown of the various adverse events reported is as follows: cough (OR: 1.4, 95\% CI: $0.1-13.5)$, headache (OR: 0.9, 95\% CI: $0.4-2.0$ ), diarrhoea (OR: 0.8, 95\% CI: 0.4 - 1.6), nasal symptoms (congestion, rhinitis, dry or sore throat) (OR: 1.0, 95\% CI: $0.5-2.0$ ), nausea (OR: $0.6,95 \% \mathrm{CI}: 0.4-1.1$ ), bronchitis or pneumonia (OR: $0.7,95 \%$ CI: $0.2-2.3$ ) and all types of adverse events (OR: 0.9, 95\% CI: $0.7-1.1$ ), Table 4.

\subsection{Treatment in children}

Zanamivir to treat children is not associated with increased adverse events in comparison with placebo [2]. However, this finding is based on data from just one study. Adverse events, and serious adverse events, were similar $\mathrm{OR}=0.8$, (95\% CI: $0.5-1.2)$, and OR = 3.3 (95\% CI: $0.1-8.2)$, respectively, Table 4. Adverse events leading to study withdrawal could not be assessed reliably because they were reported so infrequently.

\section{Conclusion}

These data on neuraminidase inhibitors are somewhat limited by limited good quality adverse event data available. The majority of safety outcomes are based on evidence from just one or two randomised, controlled trials. Consequently, 95\% confidence intervals are wide and do not rule out the possibility of clinically important adverse events from these drugs in addition to those reported here.

Oseltamivir administered as prophylaxis in healthy adults was associated with increased nausea. The causal effect is supported by the dose response: there was more nausea with a greater dose of drug, so that for $75 \mathrm{mg} /$ day, 20 patients had to be treated to cause one to experience nausea, compared with 13 if they took double that dose. However, there was no significant increase in vomiting. This might have been a consequence of inadequate power: the incidence of vomiting was lower than that for nausea. Nor was oseltamivir administered 
as prophylaxis at $75 \mathrm{mg}$ daily in healthy adults associated with diarrhoea, abdominal pain or other adverse events. Data for these adverse outcomes were not available for the increased dose of $150 \mathrm{mg}$ daily or for administration to children prophylactically.

Oseltamivir administered as treatment for adults was not associated with cough, headache, diarrhoea, nasal symptoms or nausea. An analysis of all adverse events combined also showed no difference between patients given oseltamivir and patients given placebo. However, all of these results, with the exception of nausea, are based on just one study of $\sim 300$ patients. The odds ratio obtained for the nausea comparison was consistent with the prophylaxis result, although there was no statistical significant difference found. In the case of children, oseltamivir administered for treatment of influenza leads to an increase in vomiting, where an additional 18 children treated would result in one additional case of vomiting. Paradoxically no increase in nausea was found, although this might be a reporting anomaly: the overall incidence of vomiting reported was much higher compared with that for nausea.

Oseltamivir was not associated with diarrhoea, serious adverse events or adverse events serious enough to warrant withdrawal from a randomised clinical trial. A comparison of any adverse event also showed no difference between groups of children treated with oseltamivir and equivalent groups treated with placebo.

Zanamivir used as a prophylaxis against influenza in healthy adults seemed to have no adverse effects. There are no data for children. As treatment in adults, it was not associated with cough, headache, diarrhoea, nasal symptoms, nausea, bronchitis or pneumonia, nor all adverse events combined.
The data on which these conclusions are based are more substantial than for oseltamivir and so one might have more confidence in them. They are based on between two and four randomised studies and between 1000 and $>2000$ patients in total. In the case of children, treatment with zanamivir was not associated with any adverse event or serious adverse events, although the data on serious adverse events is nonetheless limited.

\section{Expert opinion}

These drugs have a reasonable side effect and adverse effect profile if they are to be used to treat or protect patients against a life-threatening disease. However, if neuraminidase inhibitors are to be prescribed in situations in which avoidance of inconvenience or minor discomfort is hoped for, then the balance of harms to benefits will be more difficult to judge. One might expect zanamivir to have fewer systemic side effects since it is inhaled rather taken systematically, and this is supported by the data.

Can we expect more trials to supplement and better inform these conclusions? First, potential trialists would have to convince ethics committees that there is sufficient uncertainty about the cost-benefit of the drugs in prophylaxis and treatment of influenza to approve further work. Another source of data might come from use of these drugs for other diseases, such as $\mathrm{H} 5 \mathrm{~N} 1$ disease (the human form of avian influenza), for which they are currently recommended [108]. Another again would come from widespread use of the drug and observational data, often the source of rare or uncommon adverse events of drugs.

\section{Bibliography}

Papers of special note have been highlighted as either of interest $(\bullet)$ or of considerable interest $(\bullet)$ to readers.

1. JEFFERSON T, DEMICHELI V, RIVETTI D, JONES M, DI PIETRANTON J C, RIVETTI A: Antivirals for influenza in healthy adults: systematic review. Lancet (2006) 367:303-313.

-• Report on most recent systematic review of antivirals for influenza in adults.

2. MATHESON NJ, SYMMONDS-ABRAHAMS M, SHEIKH A, SHEPPERD S, HARNDEN A: Neuraminidase inhibitors for preventing and treating influenza in children. Cochrane Database Syst. Rev. (2003) Issue 3.

-• Systematic review of neuraminidase inhibitors for influenza in children.
3. PAPANIKOLAOU P, CHRISTIDI G, IOANNIDIS J: Comparison of evidence on harms of medical interventions in randomized and nonrandomized studies. CMAJ (2006) 174:635-641.

4. TURNER D, WAILLO A, NICHOLSON K, COOPER N, SUTTON A, ABRAMS K: Systematic review and economic decision modelling for the prevention and treatment of influenza $\mathrm{A}$ and B. Health Technol. Assess. (2003) 7(35):1-170.

- Systematic review of antivirals for influenza in adults, the elderly and children.

5. HAYDEN FG, ATMAR RL, SCHILLING M et al: : Use of the selective oral neuraminidase inhibitor oseltamivir to prevent influenza. N. Engl. J. Med. (1999) 341(18):1336-1343.
6. KASHIWAGI S, KUDOH S, WATANABE A, YOSHIMURA I: Efficacy and safety of the selective oral neuraminidase inhibitor oseltamivir for prophylaxis against influenza: placebo-controlled double-blind multicenter Phase III trial. J. Jpn. Assoc. Infect. Dis. (2000) 74(12):1062-1076.

7. LI L, CAI B, WANG M, ZHU Y: A double-blind, randomized, placebo-controlled multicenter study of oseltamivir phosphate for treatment of influenza infection in China. Chin. Med. J. (2003) 116(1):44-48.

8. KASHIWAGI S, KUDOH S, WATANABE A, YOSHIMURA I:

Clinical efficacy and safety of the selective oral neuraminidase inhibitor oseltamivir in treating acute influenza: placebo-controlled double-blind multicenter Phase III trial. J. Jpn. Assoc. Infect. Dis. (2000) 74(12):1044-1061. 
9. TREANOR JJ, HAYDEN FG, VROOMAN PS et al:: Efficacy and safety of the oral neuraminidase inhibitor oseltamivir in treating acute influenza: a randomized controlled trial. JAMA (2000) 283(8):1016-1024.

10. WHITLEY R, DUTKOWSKI R, IPE D, WARD P: Safety and acceptability of oseltamivir liquid formulation in the treatment of influenza in children aged 1 to 12 years. 9th International Congress on Infectious Diseases. Buenos Aires, Argentina (2000).

11. WHITLEY RJ, HAYDEN FG, REISINGER KS et al: Oral oseltamivir treatment of influenza in children. Pediatr. Infect. Dis. J. (2001) 20(2):127-133.

12. THE MIST (MANAGEMENT OF INFLUENZA IN THE SOUTHERN HEMISPHERE TRIALISTS) STUDY GROUP: Randomised trial of efficacy and safety of inhaled Zanamivir in treatment of influenza $A$ and $B$ virus infection. Lancet (1998) 352:1877-1085.

13. PUHAKKA T, LEHTI $\mathrm{H}$, VAINIONPAEAE R et al:: Zanamivir: a significant reduction in viral load during treatment in military conscripts with influenza. Scand. J. Infect. Dis. (2003) 35(1):52-58.

14. MATSUMOTO K, OGAWA N, NEROME K et al: Safety and efficacy of the neuraminidase inhibitor zanamivir in treating influenza virus infection in adults: results from Japan GG167 Group. Antiviral Therapy (1999) 4(2):61-68.
15. MONTO AS, FLEMING DM, HENRY D et al:: Efficacy and safety of the neuraminidase inhibitor zanamivir in the treatment of influenza A and B virus infections. J. Infect. Dis. (1999) 180(2):254-261.

16. MAKELA MJ, PAUKSENS K, ROSTILA T et al.: Clinical efficacy and safety of the orally inhaled neuraminidase inhibitor zanamivir in the treatment of influenza: a randomized, double-blind, placebo-controlled European study. J. Infect. (2000) 40(1):42-48.

17. HEDRICK JA, BARZILAI A, BEHRE U et al: Zanamivir for treatment of symptomatic influenza A and B infection in children 5 to 12 years of age: a randomized controlled trial. Pediatr. Infect. Dis. J. (2000) 19(5):410-417.

\section{Websites}

101. http://www.who.int/mediacentre/factsheets/ fs $211 /$ en

World Health OrganizationInfluenza fact sheet.Number 211 (2003).

102. http://www.fda.gov/cder/drug/infopage/tamiflu /default.htm

US Food and Drug Administration: Tamiflu (oseltamivir phosphate) (2005).

103. http://www.fda.gov/cder/news/relenza/default. htm

US Food and Drug Administration: Relenza (zanamivir) (2006).

104. http://www.emea.eu.int/humandocs/Humans/ EPAR/tamiflu/tamiflu.htm European Medicines Agency: European Public Assessment Report (2006).
105. http://www.emea.eu.int/pdfs/human/pande micinfluenza/33997205.pdf

European Medicines Agency: Summary Report: Review on influenza antiviral medicinal products for potential use during a pandemic (2005).

106. http://www.tamiflu.com/safety.asp Roche Laboratories, Inc.: Tamiflu safety information (2006).

107. http://www.relenza.com/40_SafetyInfo.html GlaxoSmithKline: Important safety information about Relenza (2006).

108. http://www.who.int/csr/disease/avian_influen za/guidelines/pharmamanagement/en/index .html.

WHO: Rapid Advice Guidelines on pharmacological management of humans infected with avian influenza A (H5N1) virus (2006).

\section{Affiliation}

Mark Jones $^{\dagger 1} \mathrm{PhD} \&$ Chis Del Mar ${ }^{2} \mathrm{MA}, \mathrm{MB}$, BChir, MD, FRACGP, FAFPHM

${ }^{\dagger}$ Author for correspondence

${ }^{1}$ Biostatistician, University of Queensland, Princess Alexandra Hospital, School of Population Health, Woolloongabba, Queensland 4102, Australia Tel: +61 73240 5990; Fax: +61 73240 5112; E-mail: m.jones@sph.uq.edu.au ${ }^{2}$ Dean of Health Sciences and Medicine, Bond University, Faculty of Health Sciences and Medicine, Gold Coast, Queensland 4229, Australia

Tel: +61 75595 5499; Fax: +61 75595 4122; E-mail: cdelmar@staff.bond.edu.au 